side, where its favourite haunts are Labrador and Newfoundland, it is still so abundant that many thousands are at times taken by a single vessel. March is the breedingtime, and at this season the young are produced on the ice far away from land. All previous writers with which we are acquainted state that the young are born in the white coat, which is not exchanged for the grey till the lapse of about twelve months. But Commander Robinson is positive that this is incorrect, and that the grey coat is assumed previous to birth. Unfortunately there are no specimens in the British Museum available for deciding this disputed point ; but it is earnestly to be hoped that such may be supplied before long. In the meantime it may be suggested that the discrepancy has arisen from the young of one species having been mistaken for that of another, although it is at the same time difficult to see how this can have been the case with a seal so peculiar in appearance, and dwelling so much apart as does the present.

The above are but a few of the leading features in the habits of the northern ice-seals, to describe which in detail would require a small volume. Among the points which require special elucidation are what becomes of the great bulk of the harp-seals between their visits to Greenland in May and September, the mode in which scals make their breathing-holes, and the colour of the newly-born crested seal.

R. L.

\section{MAGNETIC AND PENDULUM} OBSER VATIONS. ${ }^{1}$

$\mathrm{I}^{\mathrm{T}}$ may be remembered that Lieutenant Peary, before starting on his sixth expedition to Greenland in 1896 , offered transport on his steamer to two parties of scientific men, and that the opportunity was very properly accepted. The parties--which were under the direction respectively of Prof. A. E. Burton, of the Massachusetts Institute of Technology, and Prof. R. S. Tarr, of Cornell University-consisted each of six members, and were entirely independent in organisation and equipment of the main body of the expedition. The researches of the Boston party consist of observations in terrestrial physics, including glacier phenomena, and studies of Eskimo life, and their reports are now coming to hand. The report of Mr. G. R. Putnam, of the United States Coast and Geodetic Survey, who undertook the magnetic and pendulum observations, is now before us.

Early in July Mr. Putnam left Boston with a complete outfit of magnetic, pendulum, and astronomical instruments, and arrived at Halifax, Nova Scotia, two days later. Here he found time to make magnetic determinations at the Naval Dockyard, at which station the declination observations cover a period of nearly three centuries. Reaching Sydney, Cape Breton, the starting point of the expedition proper, six days elapsed before the departure of the Hope, Lieutenant Peary's steamer, and in this time all the instruments were set up and used. The voyage along the Labrador coast was only interrupted by a few hours' stop at Turnavik, where magnetic observations were made. Passing up the Hudson Straits, Mr. Putnam spent two days at Ashe Inlet, but here a gale on the second night unfortunately interfered with the full success of his work. The Hope then turned eastward, and on August $I$ the coast of Greenland was sighted. Magnetic observations only were made at Godhavn, and Umanak was reached a day or two after. Here Mr. Putnam's party landed and settled down for a month, while the Hope continued her northern voyage. The required observations having been completed, the whole party indulged in exploring

1 "The Scientific Work of the Boston Party on the Sixth Peary Expedition to Greenland. Report A."

No. I 476 , vOL. 57$]$ trips, but on these excursions they could not well take the magnetic instruments. On the return of Lieutenant Peary, the homeward journey began. After the magnetic observations at Godhavn had been repeated, the ship anchored at Niantilik, in Cumberland Sound, where observations were again attempted, but here the value of the pendulum observations was lessened, because unfavourable weather did not allow the necessary timeobservations. Sydney was again reached September 26, and here a few observations were taken, prior to the instruments being shipped to Washington, where they were tested and found to be unaffected by their long journey of 5000 miles.

The magnetic outfit, comprising a dip circle of the ordinary Kew pattern and a magnetometer, was lent by the Coast and Geodetic Survey. In the case of the latter instrument, the magnet consisted of a hollow octagonal prism of steel, held in a stirrup with a long arm to which the two silk fibres were attached. By this arrangement the magnet remained sensibly horizontal at ordinary latitudes, but a copper balancing ring was sometimes used at the most northerly stations. The formula used for computing the moment of inertia of this ring (p.74) is incorrect, and the term $\frac{1}{3}\left(x_{2}^{2}+x_{2} x_{1}+x_{1}^{2}\right)$ should be replaced by $\frac{1}{4}\left(x_{2}+x_{1}\right)^{2}$, although the numerical correction happens to be insensible. For determining the azimuth by the sun, the magnet box is removed from the base and circle, and the latter is then used with a separate theodolite.

Mr. Putnam's results in this part of his work are both valuable and interesting. Further evidence has been obtained of the violence of magnetic disturbances in polar regions, although far greater disturbances have been recorded. Thus the range in a day observed at Niantilik exceeded $4 \frac{1}{2}$ degrees, a change of over 3 degrees being noticed in twenty minutes. A comparison with the contemporary record at Washington reveals, it is true, that an unusual magnetic storm visited this city, but its severity as measured by the range of declination was fifteen times less than that at the northern station. With the exception of Niantilik, earlier information is available with regard to all the stations visited by Mr. Putnam; and although only Halifax and Godhavn possess satisfactory records extending over the last three-quarters of a century, the general tendency in the change of the magnetic elements seems to be clearly indicated. At present it appears that at all these points "the westerly declination is diminishing, the northerly dip is diminishing, the horizontal force is increasing, and the total force is diminishing."

The apparatus used for determining the relative force of gravity, comprised a set of three half-second pendulums, one sidereal and two mean time chronometers, and a meridian telescope. The pendulums were swung in an air-tight case, in which the pressure was reduced to about $6 \mathrm{~cm}$. by means of an air-pump. All the chronometers were provided with electrical break circuit attachments, and were thus capable of the instantaneous raising of a shutter by an electrical mechanism and the momentary illumination of a slit every second or two seconds. By this means the reflections of a flash in two mirrors, one attached to the fixed knife edge, and the other to the head of the pendulum, could be observed in a telescope. The period of the pendulum was then deduced from the observed coincidences. At the southern stations coincidences were observed with sidereal seconds, but nearer the pole, with mean time seconds, on account of the decrease in the period of the pendulum. Whenever the plan could be carried out each pendulum was swung for: a period of eight hours, both in reversed and direct positions, and star observations were made at the beginning and end of the forty-eight hours. The following table summarises the principal results (p. 103):- 


\begin{tabular}{|c|c|c|c|c|c|}
\hline Station. & $\begin{array}{c}\text { Latitude } \\
\text { N. }\end{array}$ & $\begin{array}{l}\text { Longitude } \\
\text { W. of } \\
\text { Green- } \\
\text { wich. }\end{array}$ & $\begin{array}{l}g_{1}, \\
\text { reduced to } \\
\text { sea level. }\end{array}$ & $\begin{array}{l}g_{0}, \\
\text { theoretical } \\
\text { value. }\end{array}$ & $g_{1}-g_{0}$ \\
\hline $\begin{array}{l}\text { Washington } \\
\text { Sydney (Cap }\end{array}$ & we $3^{8} 53$ & $77 \stackrel{1}{1}$ & $\begin{array}{c}\mathrm{cm} . \\
980^{\circ} \text { IOI }\end{array}$ & $\begin{array}{c}\mathrm{cm} . \\
90^{\circ} \circ 0^{\circ} 7\end{array}$ & $\begin{aligned} & \mathrm{cm} . \\
+ & 0 \% 14\end{aligned}$ \\
\hline $\begin{array}{l}\quad \text { Breton) } \\
\text { Ashe Inlet } \\
\text { Umanak } \\
\text { Niantilik }\end{array}$ & $\begin{array}{rrr}\ldots & 46 & 9 \\
\ldots & 62 & 33 \\
\ldots & 70 & 40 \\
\ldots & 64 & 53\end{array}$ & $\begin{array}{lr}60 & 12 \\
70 & 35 \\
52 & 8 \\
66 & 20\end{array}$ & $\begin{array}{l}980^{\circ} 722 \\
982^{*} 109 \\
982^{*} 594 \\
982^{*} 275\end{array}$ & $\begin{array}{l}980^{\circ} 73^{2} \\
982 \cdot 104 \\
982 \cdot 632 \\
982 \cdot 271\end{array}$ & $\begin{array}{l}-0.010 \\
+0.005 \\
-0.038 \\
+0.004\end{array}$ \\
\hline
\end{tabular}

The theoretical value is that given by the assumed formula,

$$
g_{\theta}=978.066 \text { ( } 1+0.005243 \sin ^{2} \text { latitude), }
$$

and $g_{1}$ is obtained by using Bouguer's formula.

It would not be easy to over-estimate the value of these accurate determinations of gravity, for they help to fill a very serious gap in the series of observations which have been made in various parts of the world. Prof. Helmert's recent report to the International Geodetic Association has shown that no pendulum observations had been obtained in the region visited by Mr. Putnam, and it is in the polar regions that data as to the variations of gravity are of the greatest importance and, therefore, most urgently required. Mr. Putnam concludes his report with some historical notes on the development of apparatus and the progress of research, which are very interesting. It is hardly correct, however, to say that the law $t=\pi \sqrt{\frac{l}{g}}$ applies even to the ideal simple pendulum (p. I Io). These notes contain a good account of the controversy which has arisen about the appropriateness of the second term in Bouguer's formula for the reduction of $g$ to sea level : $d g=\frac{2 g \mathrm{H}}{r}\left(\mathrm{I}-\frac{3 \delta}{4 \Delta}\right)$, where $\delta$ is density of matter lying above sea level, and $\Delta$ is the mean density of the earth. The value of pendulum observations as affording indications of surface density is insisted upon, and a practical application of the method is suggested. It is to be hoped that Mr. Putnam will see his project realised, by which the relative proportions of ice and rock in the great Greenland elevation may be determined by pendulum experiments.

\section{RAINFALL OF THE UNITED STATES}

UNER this title the Weather Bureau of the Department of Agriculture has published a bulletin containing a discussion of the observations obtained from the longest and most trustworthy rainfall registers in the United States, accompanied by annual, seasonal, and other charts. In addition to the usual tables of the mean monthly and annual precipitation, arranged according to geographical distribution, an important cleparture has been made by separately discussing the rainfall of the crop-growing season ; for, as the author remarks, however valuable a knowledge of the water supply throughout the year may be, information as to the amount of rainfall available for agricultural purposes is possibly of greater consequence.

Another departure from the ordinary treatment of the subject is the discussion of the monthly distribution by districts and types according to natural boundaries. The conditions favourable for rainfall are chiefly (I) nearness to the ocean, (2) proximity to the track of storms, and (3) the position of mountain ranges. The rainfall of the North Pacific coast is quoted as an example of the combined effect of all three conditions, the distinguishing characteristic of this type being a wet season from October to March, and a practically rainless summer, except in Northern California and parts of Oregon and Washington. About half of the yearly fall occurs between December and February. The rainfall is discussed under twelve such types; we are unable to refer specially to each of these, but the chart of mean annual precipitation shows NO. [ 476 , vOL. 57$]$ that there is a narrow belt on the north-west coast, extending from Cape Flattery on the north to midway of the Oregon coast on the south, and some distance inland, where the annual amount exceeds 50 and at some points Ioo inches. Eastward and southward the annual fall diminishes, reaching a minimum on the lowlands and valleys between the Coast Range on the west and the Sierra Nevada and the Cascade Ranges on the east, where the amount in some cases does not exceed ro inches, but in years of plentiful rainfall as much as 20 inches may fall in the best-watered parts. At Terrace (Utah), a station on the Central Pacific Railroad, the mean annual fall is only 4.3 inches, and in the driest year was as low as 0.7 inch. To the eastward of the Rocky Mountains the annual fall is from Io to 18 inches, and increases slowly to 60 inches on the Florida and Gulf coasts, and from 40 to 50 inches in the Eastern States. There is, however, a gradual clecline both from the Atlantic coast westward and from the Gulf coast northward. In considering the various rainfall values in this discussion allowance must he made for the position of the gauges which are generally exposed on roofs, owing to the stations being mostly in towns. It is well known that the amount caught in the gauge decreases with altitude above the ground, and it is estimated that the loss from this cause in the values quoted by the Weather Bureau is from 5 to Io per cent. of the total annual fall. With regard to the important subject of excessive rainfall, down to the year I 888 only one self-recording gauge was in use at the Signal Service stations; five others were added in 1889 , and the publication in the Monthly Weather Review of the maximum falls in five and ten minutes, and also in one hour, were begun. In August I 890 a cloud-burst passed over Palmetto (Nevada), when a gauge that was not exposed to the full intensity of the storm caught 8.8 inches of water in an hour, and in August $189 \mathrm{I}, 1 \mathrm{I} \frac{1}{2}$ inches were measured within an hour at Campo (California). The great majority of excessive rains are said to occur east of longitude $105^{\circ} \mathrm{W}$., and principally in the summer months, in connection with afternoon thunderstorms; they occasionally take place in the track of West India hurricanes, and are more abundant on the Gulf and South Atlantic coasts than at inland places. The maximum rates of rainfall per hour, estimated from periods of five minutes, at the Weather Bureau Stations which possess self-registering gauges, were 9 inches at Bismarck (N. Dakota); 8.4 inches at St. Paul (Wisconsin), and 8.2 inches at New Orleans.

This valuable memoir has been prepared by $\mathrm{Mr}$. A. J. Henry, under the direction of Prof. Willis L. Moore, the Chief of the Weather Bureau.

\section{NOTES.}

The German Emperor, as King of Prussia, has conferred upon Dr. John Murray, Director of the Scottish Marine Station, and formerly of the Challenger expedition, the rare distinction of knighthood in the Order Pour le Mírite founded by Frederick the Great. This is generally allowed to be the highest honour which a man of science can receive, and is limited to thirty German and twenty-five foreign knights. Lord Kelvin, Lord Lister, and Sir G. G. Stokes are the only other British men of science now alive who have received the Order. Dr. Murray has also been elected a Foreign Member of the Imperial Russian Academy of Sciences.

ThE Committee appointed by the American Society of Naturalists to inquire into the practicability and feasibility of the exploration of the Antarctic continent, report that an expenditure of from forty thousand to fifty thousand dollars would suffice for an independent scientific expedition. The Committee suggests that if this fund could not be raised by 